\title{
Interaction between antigen presenting cells and autore- active $T$ cells derived from BXSB mice with murine lupus
}

\author{
Peng Yang ${ }^{1}$, Bo Li ${ }^{1}$, Ping Lv ${ }^{1}$, Yan Zhang ${ }^{1}$, Xiao-Ming Gao ${ }^{1}$ \\ ${ }^{1}$ Department of Immunology, Peking University Health Science Center, Peking University, 38 Xueyuan Rd, Beijing 100083, China
}

\begin{abstract}
Systemic lupus erythematosus (SLE) is a typical autoimmune disease involving multiple systems and organs. Ample evidence suggests that autoreactive T cells play a pivotal role in the development of this autoimmune disorder. This study was undertaken to investigate the mechanisms of interaction between antigen presenting cells (APCs) and an autoreactive T cell (ATL1) clone obtained from lupus-prone BXSB mice. ATL1 cells, either before or after $\gamma$-ray irradiation, were able to activate naive B cells, as determined by B cell proliferation assays. Macrophages from BXSB mice were able to stimulate the proliferation of resting ATL1 cells at a responder/stimulator $(\mathrm{R} / \mathrm{S})$ ratio of $1 / 2.5$. Dendritic cells (DCs) were much more powerful stimulators for ATL1 cells on a per cell basis. The T cell stimulating ability of macrophages and B cells, but not DCs, was sensitive to $\gamma$-ray irradiation. Monoclonal antibodies against mouse MHC-II and CD4 were able to block DC-mediated stimulation of ATL1 proliferation, indicating cognate recognition between ATL1 and APCs. Our data suggest that positive feedback loops involving macrophages, B cells and autoreactive $\mathrm{T}$ cells may play a pivotal role in keeping the momentum of autoimmune responses leading to autoimmune diseases.
\end{abstract}

Keywords: SLE, T cells, antigen presenting cells

Cell Research (2007) 17:556-564. doi: 10.1038/sj.cr.7310146; published online 13 February 2007

\section{Introduction}

Production of autoantibodies against double-stranded DNA (dsDNA) is the hallmark of systemic lupus erythematosus (SLE), a typical autoimmune disease involving multiple systems and organs [1-3]. Ample evidence suggests that autoreactive $\mathrm{T}$ cells play a pivotal role in the development of this prototype autoimmune disorder [2-8]. Mechanisms underlying the generation and expansion of autoreactive T cells in vivo are of considerable interest for our understanding and management of SLE. It has been suggested that lupus T cells are hyperactive [9]. Interestingly, Zhu, et al. have recently demonstrated that intrinsic abnor-

\footnotetext{
Correspondence: Xiao-Ming Gao

Tel/Fax: +86-10-82801156

E-mail: xmgao@bjmu.edu.cn

Abbreviations: SLE (systemic lupus erythematosus); ATL (autoreactive T lymphocyte); APC (antigen presenting cell); DC (dendritic cell); GM-CSF (granulocyte/macrophage colony stimulating factor)

Received 5 September 2006; revised 26 Novemember 2006; accepted 6 December 2006; published online 13 February 2007
}

malities in Sle 3 gene expression in antigen presenting cells (APC), including dendritic cells (DC) and macrophages, may dictate several of the phenotypes associated with systemic lupus, including T cell hyperactivity [10]. It is reasonable to postulate that the abnormal interplay between autoreactive T cells and APCs, rather than hyperactivity of $\mathrm{T}$ cells and/or abnormality of APCs alone, may play a more important role in the development of SLE.

$\mathrm{BXSB}$, a recombinant inbred mouse strain derived from a cross between C57BL/6 $\left(\mathrm{H}-2^{\mathrm{b}}\right)$ female and $\mathrm{SB} / \mathrm{Le}\left(\mathrm{H}-2^{\mathrm{b}}\right)$ male mice [11], represents one of the most extensively studied animal models for SLE. Adult male BXSB mice exhibit characteristics similar to that in human disease, such as production of autoantibodies against dsDNA and other nuclear antigens, inflammatory reaction in the joints and development of nephritis in later stage of the disease [12-14]. The Yaa (Y chromosome-linked autoimmune accelerating) gene of BXSB mice has been shown to accelerate the progress of autoantibody production and disease manifestation in lupus-prone animals [13, 14]. Genome wide linkage studies have shown that the BXSB mouse model involves at least 6 distinct intervals located 
on Chromosomes 1, 3, 10 and 13, all of which map to $\mathrm{SB} /$ Le-derived regions [14-16].

In a previous study, we characterized an autoreactive $\mathrm{CD}^{+}$Th1 clone, ATL1, from 6-month-old male BXSB mice with elevated titres of anti-dsDNA serum Abs [6]. The ATL1 cells expressed TCR- $V \beta$ 2.1-J $\beta 2$ and $V \alpha 10.1-J \alpha 15$ chains and vigorously proliferated in response to stimulation with syngeneic splenocytes in vitro. Moreover, they were able to help syngeneic B cells to produce anti-dsDNA and anti-histone autoantibodies in vitro as well as in vivo [6]. The present study was undertaken to investigate the mechanisms of interaction between APCs and autoreactive T cells, using ATL1 as a representative for autoreactive T cells. Results arising from this study may provide useful clues for our understanding of the mechanisms of autoimmune disease development.

\section{Materials and Methods}

\section{Mice and monoclonal Abs}

BXSB mice were imported from Jackson Labs, USA and maintained at the animal facilities of Department of Immunology, Peking University Health Science Center, Beijing, China. C57BL/6 mice were provided by the Experimental Animal Center, PKU Health Science Center, Beijing, China. Male mice of 5-6 months of age were used in this study.

Purified rat or hamster mAbs against mouse MHC class II, CD4, CD8 and FITC- or R-PE-conjugated rat anti-mouse CD80 (B7.1), CD19 and CD11c mAbs were purchased from BD PharMingen (San Diego, California, USA).

\section{Cell culture medium and the autoreactive T cell clone}

All cells were cultured in R10: RPMI-1640 (Sigma, USA) supplemented with $10 \%(\mathrm{v} / \mathrm{v})$ FCS (Hyclone, USA), penicillin/streptomycin $(100 \mathrm{U} / \mathrm{ml}), \mathrm{L}$-glutamine $(2 \mathrm{mM})$ and $2-\mathrm{ME}\left(5 \times 10^{-5} \mathrm{M}\right)$. The autoreactive T cell clone, ATL1, was described previously [6]. The ATL1 cells were maintained by weekly stimulation and expansion with irradiated syngeneic spleen cells $\left(2 \times 10^{5}\right)$ and recombinant IL-2 (20 IU/ml) (Clinical Grade, BRUCP Co., Beijing, China).

\section{Proliferation assays}

ATL1 cells $\left(1 \times 10^{4}\right)$ were incubated in 96-well flat bottomed plates (Nunc, Denmark) with irradiated stimulator cells (splenocytes, DCs, macrophages or B cells) in a total volume of $200 \mu 1 \mathrm{R} 10$. The cultures were incubated at $37^{\circ} \mathrm{C}$ and $5 \% \mathrm{CO}_{2}$ for $3 \mathrm{~d}$. In the last $8 \mathrm{~h}$ of incubation, $0.5 \mu \mathrm{Ci}^{3} \mathrm{H}$-thymidine $\left({ }^{3} \mathrm{H}\right.$-TdR) was added into each well. The cells were then harvested, using a 96-well plate harvester (Tomtec, USA), onto fiber glass filters and radioactivity on the filter matt was counted in a MicroBeta Trilux LSC counter (EG\&G Wallac, USA).

\section{Preparation of splenic adherent cells, B cells and peritoneal macrophages}

For preparation of splenic adherent cells, splenocytes freshly collected from BXSB and C57BL/6 mice were cultured in Petri-dishes in $\mathrm{R} 10$ medium at $37{ }^{\circ} \mathrm{C}, 5 \% \mathrm{CO}_{2}$ for $4 \mathrm{~h}$, allowing adherent cells to adhere to the plastic surface. Non-adherent cells were gently washed out. After further washes with PBS, adherent cells were collected using cell scraper.

B cells were purified from BXSB splenocytes using MicroBeads coated with rat anti-mouse CD19 mAbs (Miltenyi Biotec, Bergisch Gladbach, Germany). Purity of isolated B cells were identified by FACS (Cell purity $>95 \%$ ).

For preparation of peritoneal macrophages, ice-cold PBS (2 ml) was injected into the abdominal cavity of BXSB and C57BL/6 mice (sacrificed immediately before the experiment) followed by gentle massaging of the abdomen. The fluid containing macrophages was aspirated out using pippets. The procedure was repeated 3 times in order to get more macrophages from each animal.

\section{Preparation of bone marrow-derived DCs}

Dendritic cells were prepared using the protocol of Son et al with minor modifications [11]. Briefly, bone marrow was flushed out from the femur and tibiae of BXSB mice and incubated at a starting concentration of $2 \times 10^{6}$ cells $/ \mathrm{ml}$ in R10 in 6-well flat bottomed plates (Falcon, USA) at $37{ }^{\circ} \mathrm{C}, 5 \% \mathrm{CO}_{2}$ for $3 \mathrm{~h}$. Non-adherent cells were removed before recombinant mouse GM-CSF and IL-4 (PeproTech EC Ltd, UK) were added to the culture ( $20 \mathrm{ng} / \mathrm{ml}$ final concentration). On d 3 and 5, half of the medium was replaced with fresh medium containing rmGM-CSF and rmIL-4. On d 7, non-adherent cells were harvested, as bone-marrow-derived DCs, and examined under microscope and also by flow cytometry for expression of CD11c.

\section{CFSE labeling and cell cycle analysis}

ATL1 cells, resuspended at $1 \times 10^{7} / \mathrm{ml}$ in PBS, were treated with $5 \mu \mathrm{M}$ (final concentration) CFSE (5-(and-6)-carboxyflurescein diacetate succinimidyl ester, Molecular Probes, Eugene, OR, USA) for $10 \mathrm{~min}$ at $37^{\circ} \mathrm{C}$. The unconjugated CFSE was eliminated by washing the cells with FCS supplemented RPMI 1640. The labeled ATL1 cells were co-cultured with viable, or 1500 Rads-irradiated, splenic $\mathrm{B}$ cells for $72 \mathrm{~h}$, and then the cells were harvested and fixed with $70 \%$ cold ethanol for $16-18 \mathrm{~h}$ at $4{ }^{\circ} \mathrm{C}$. After washes by PBS twice, the cells were treated by $20 \mu \mathrm{g} / \mathrm{ml}$ RNaseA for $30 \mathrm{~min}$ at $37^{\circ} \mathrm{C}$, and stained with PI immediately before flow cytometric analysis. Only CFSE-positive cells were gated for cell cycle analysis (FL2-A).

\section{Statistical analysis}

All experiments were repeated at least 3 times. Statistical significance was calculated using student's $t$-test. $P<0.05$ were considered significant.

\section{Results}

\section{Activation of naive BXSB B cells by ATL1 cells in vitro}

To investigate the effect of autoreactive $\mathrm{T}$ cells on $\mathrm{B}$ cell activation, ATL1 cells were irradiated and then used to stimulate the proliferation of purified naive B cells from BXSB mice. As shown in Figure 1, irradiated ATL1 cells, but not freshly isolated $\mathrm{CD}^{+} \mathrm{T}$ cells from 5 -month-old male $\mathrm{BXSB}$ or $\mathrm{C} 57 \mathrm{BL} / 6$ mice, were able to drive the proliferation of syngeneic B cells in vitro. Moreover, activation of BXSB B cells by ATL1 led to up-regulation of B7-1 molecules on their surface (Figure 2). 
Splenic adherent cells as stimulators for ATL1 cells

We previously demonstrated that splenocytes from $\mathrm{BXSB}$ and $\mathrm{C} 57 \mathrm{BL} / 6$ mice were able to stimulate the proliferation of ATL1 cells [6]. To further characterize the APCs in the splenocyte population responsible for ATL1 stimulation, splenocytes from 5-month-old male BXSB and $\mathrm{C} 57 \mathrm{BL} / 6$ were fractionated into adherent (mainly macrophages and DCs) and non-adherent (mainly T and B cells) cells, which were then used as stimulators in ATL1 proliferation assays. As illustrated in Figure 3, the optimal

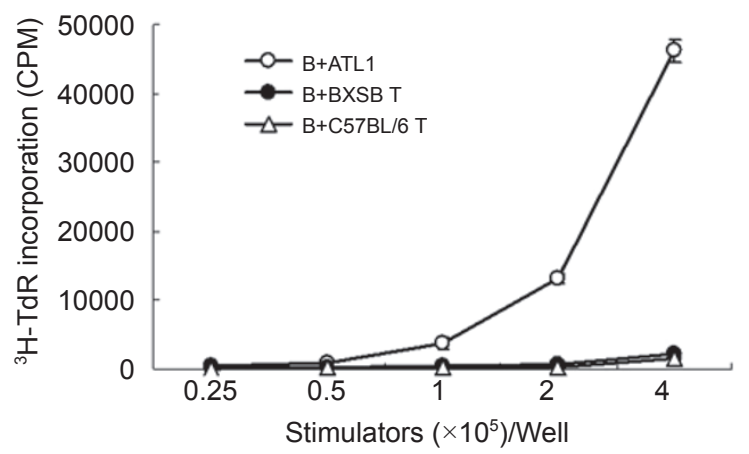

Figure 1 Activation of polyclonal B cells by irradiated ATL1 cells in vitro. Purified BXSB B cells $\left(1 \times 10^{4}\right.$ cells/well $)$ were co-cultured with 1500 Rads irradiated ATL1 cells, or freshly purified BXSB or C57BL/6 T cells for $3 \mathrm{~d}$. The cultures were pulsed with ${ }^{3} \mathrm{H}-\mathrm{TdR}$ for $8 \mathrm{~h}$ before harvesting and the results are expressed as ${ }^{3} \mathrm{H}-\mathrm{TdR}$ incorporation (CPM). responder/stimulator $(\mathrm{R} / \mathrm{S})$ ratios with splenic adherent cells and unfractionated splenocytes were 1:1 and 1:20 (with $1 \times 10^{4}$ responders in a $200 \mu 1$ culture), respectively, indicating that splenic macrophages and/or DCs were the main APCs in spleen cells responsible for the stimulation of autoreactive ATL1 cells.

\section{Interaction between macrophages and ATL1 cells}

As shown in Figure 4, peritoneal macrophages from BXSB and C57BL/6 mice were able to activate ATL1 cells with an optimal $\mathrm{R} / \mathrm{S}$ ratio of $1 / 2.5$, slightly lower than that with the splenic adherent cells. Interestingly, 1500 Rads of $\gamma$-ray irradiation completely abolished the ability of peritoneal macrophages to activate ATL1 cells in vitro. The ability of the macrophages to stimulate ATL1 was also blocked by $\mathrm{mAb}$ against the murine CD4 (Table 1). The fact that spleen adherent cells (Figure 3 ) and peritoneal macrophages (Figure 4) were able to activate ATL1 cells only at a narrow window of $\mathrm{R} / \mathrm{S}$ ratio $(1 / 2.5$ to $1 / 1)$ explains the negative results observed in our previous study where the $\mathrm{R} / \mathrm{S}$ ratio was $1 / 40$ [6].

\section{Interaction between DCs and ATL1 cells}

DCs were prepared by stimulating bone marrow (BM) cells with recombinant mouse GM-CSF and IL-4 for $7-10 \mathrm{~d}$ in vitro. The cells obtained exhibited typical DC morphology (Figure 5A) and expressed CD11c on their surface (data not shown). When the BM-derived DCs (BM-DCs) were used as APCs in vitro, they were at least 5 times more potent (on a per cell basis) than macrophages in stimulating ATL1 cells (Figure 5B). Unlike macrophages,

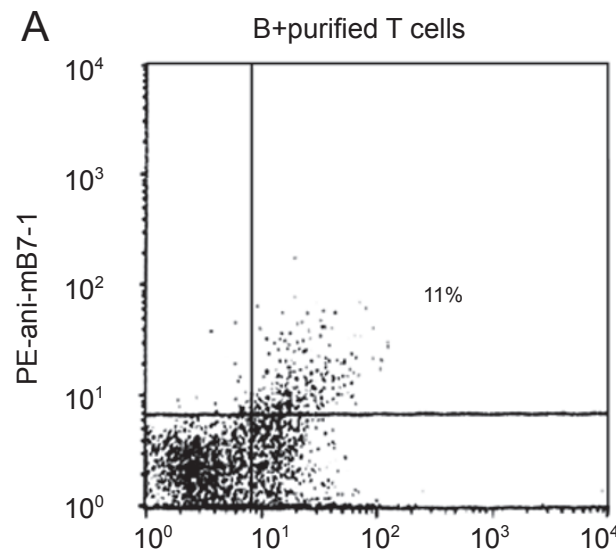

B

$10^{4}$

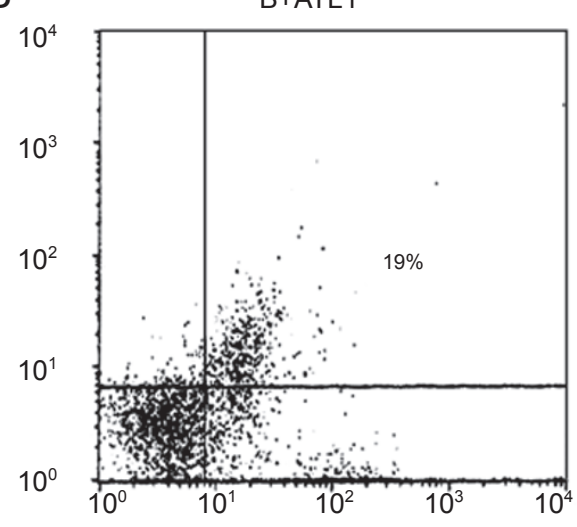

FITC-anti-mCD19

Figure 2 Elevated expression of B7.1 in BXSB B cells after stimulation with ATL1 cells. Freshly purified BXSB B cells were cocultured with freshly purified T cells from 5-month-old male BXSB mice (A) or ATL1 cells (B) for 3 days. The cells were then double stained with PE-conjugated mAb against mouse B7.1 and FITC-labeled mAb against murine CD19 followed by flow cytometric analysis. The result shown is a representative of 3 independent experiments. 


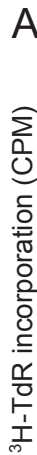

BXSB stimulators

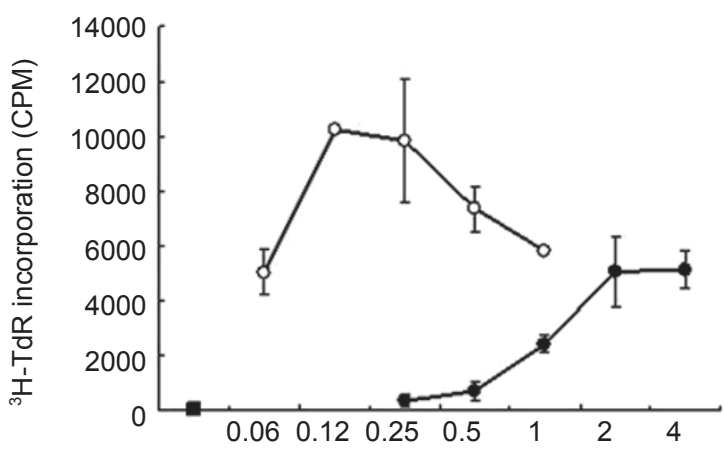

B

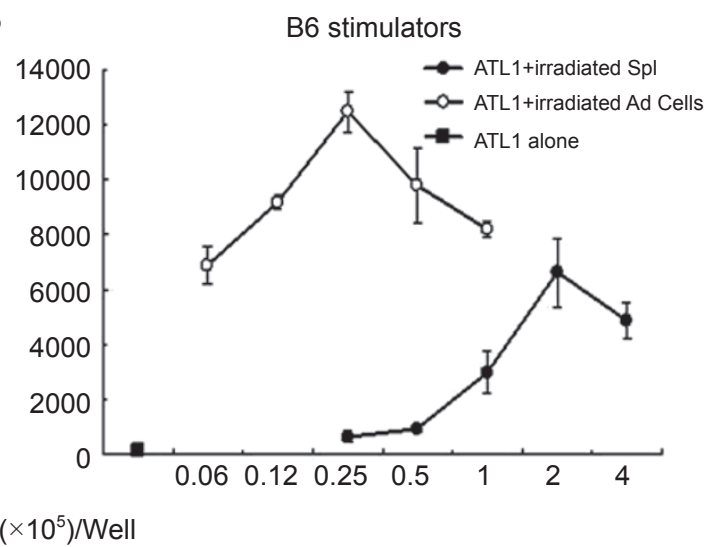

Figure 3 Splenic adherent cells as APCs for ATL1 cells. ATL1 cells $\left(1 \times 10^{4}\right.$ cells/well) were co-cultured with irradiated splenocytes or splenic adherent cells from 5-month-old male BXSB (A) or C57BL/6 (B) mice in a 72 h proliferation assay. ATL1 cells cultured alone were included as the negative control. The cultures were pulsed with ${ }^{3} \mathrm{H}-\mathrm{TdR}$ for $8 \mathrm{~h}$ before harvesting and the results are expressed as ${ }^{3} \mathrm{H}-\mathrm{TdR}$ incorporation (CPM).



Figure 4 Peritoneal macrophages as stimulators for ATL1 cells. Peritoneal macrophages, freshly prepared from 5-month-old male BXSB (A) and C57BL/6 (B) mice, were treated with or without $\gamma$-ray irradiation (1 500 Rads), and then used as stimulators for ATL1 cells $\left(1 \times 10^{4}\right.$ cells/well $)$ in a $72 \mathrm{~h}$ proliferation assay. Untreated macrophages alone and $\mathrm{T}$ cells alone were included as controls. The results are expressed as ${ }^{3} \mathrm{H}-\mathrm{TdR}$ incorporation (CPM).

the ability of DCs to activate ATL1 cells was not significantly affected by $\gamma$-ray irradiation (Figure 5B). Table 1 shows that mAbs against mouse CD4 or MHC-II were able to block DC-induced proliferation of ATL1 cells, indicating cognate recognition between ATL1 cells and DCs.

\section{$B$ cells as APCs for ATL1 cells}

Naive B cells, freshly purified from BXSB splenocytes, were treated with or without $\gamma$-ray irradiation and then employed as stimulators for ATL1 cells in T cell proliferation assays. Figure 6 demonstrates that even low dose (500 Rads) of irradiation could abolish the T-cell-stimulation ability of naive B cells. However, this does not necessarily exclude the possibility that activated B cells could activate ATL1 cells. CFSE-labeled ATL1 cells were cultured together (R/S ratio 1/20) with viable or 1500 Rads-irradiated splenic B cells for $72 \mathrm{~h}$ and were then subjected to cell cycle analysis using flow cytometry. It was clear that viable, but not irradiated B cells were able to activate ATL1 cells when co-cultured together (Figure 7). The ATL1-stimulatory effect of BXSB B cells was blocked by anti-CD4 but not anti-CD8 mAb (Table 1).

\section{Discussion}

Our data demonstrate that ATL1 cells were hyperactive 
Table 1 Inhibitory effect of mAbs on APCs -induced ATL1 proliferation ${ }^{1}$

\begin{tabular}{|c|c|c|c|}
\hline $\mathrm{APCs}$ & $\mathrm{mAbs}^{2}$ & ${ }^{3} \mathrm{H}-\mathrm{TdR}$ incorporation (CPM) & Percent inhibition $^{3}(\%)$ \\
\hline \multirow[t]{3}{*}{$\mathrm{DC}$} & Isotype control & $7157 \pm 240$ & - \\
\hline & Anti-I-A ${ }^{b}$ & $1276 \pm 469$ & $82 \%$ \\
\hline & Anti-mouse CD8 & $6789 \pm 890$ & $5 \%$ \\
\hline $\mathrm{M} \Phi$ & Isotype control & $9990 \pm 507$ & - \\
\hline \multirow[t]{3}{*}{$\mathrm{B}$} & Isotype control & $16113 \pm 1023$ & - \\
\hline & Anti-mouse CD4 & $1535 \pm 377$ & $90 \%$ \\
\hline & Anti-mouse CD8 & $13162 \pm 737$ & $18 \%$ \\
\hline
\end{tabular}

${ }^{1}$ ATL1 cells $\left(1 \times 10^{4} /\right.$ well $)$ were stimulated with syngeneic BM-DCs $\left(5 \times 10^{3} /\right.$ well $)$, peritoneal macrophages $\left(2.5 \times 10^{4} /\right.$ well $)$, B cells $\left(2 \times 10^{5} /\right.$ well $)$ for $3 \mathrm{~d},{ }^{3} \mathrm{H}$-TdR was added for the last $8 \mathrm{~h}$ before harvesting. The results are expressed as ${ }^{3} \mathrm{H}$-TdR incorporation (mean \pm standard error). ${ }^{2}$ Rat mAbs (IgG1) against murine CD4 or CD8 or hamster mAb against mouse MHC class II (IgG) or isotype control Abs were added in triplicate wells at $20 \mu \mathrm{g} / \mathrm{ml}$. Isotype of the control Abs were rat or hamster IgG.

${ }^{3}$ Percent inhibition $=[($ Control-Experiment $) /$ Control $\left.)\right] \times 100 \%$.

A

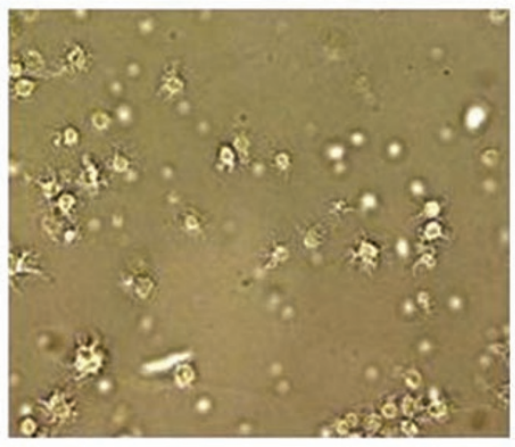

B

DCs as stimulators for ATL1 cells

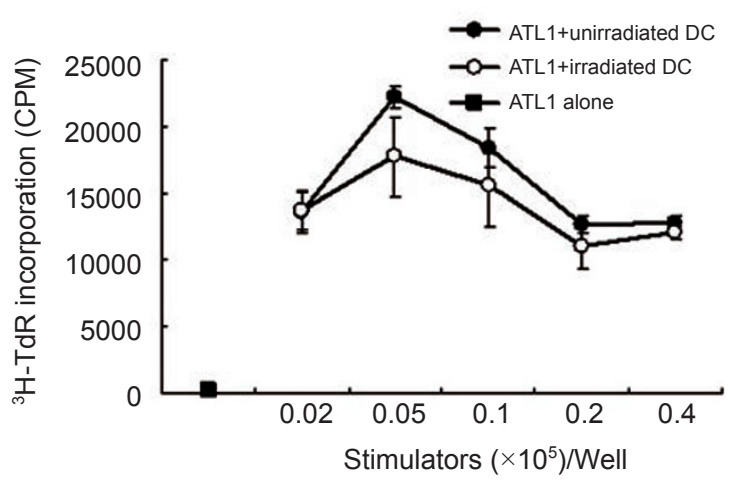

Figure 5 DCs as stimulators for ATL1 cells. DCs were prepared by stimulating BXSB mouse bone marrow cells with rmGM-CSF and rmIL-4 for 7 days. The resultant cells, photographed under a light microscope (A), were either irradiated or untreated, and then used as stimulators for ATL1 cells $\left(1 \times 10^{4}\right.$ cells/well) in a $72 \mathrm{~h}$ proliferation assay (B). The results are expressed as ${ }^{3} \mathrm{H}-\mathrm{TdR}$ incorporation $(\mathrm{CPM})$. The differences between $\mathrm{T}$ cell proliferation induced by irradiated DCs and unirradiated DCs were not statistically significant $(P>0.1$, calculated at different stimulator concentrations).

to stimulation with syngeneic APCs such as splenocytes, DCs, activated macrophages and B cells (Figures 3-7; [6]). The reactivity of ATL1 cells to activated B cells and macrophages from BXSB or B6 mice appears to be antigen non-specific (or pan-specific), but we can not exclude the possibility that ATL1 cells recognize a single self antigen, which is constitutively presented by these APCs on the cell surface in association with MHC class II. In addition, macrophages from $\mathrm{C} 57 \mathrm{BL} / 6$ mice were able to activate ATL1 cells in vitro (Figures 3 and 4). More importantly, ATL1 cells were capable of inducing IL- 1 and TNF- $\alpha$ production by macrophages [6] and driving polyclonal naive B cells to proliferate in vitro (Figure 1). The ability of ATL1 cells to activate naive B cells was almost unaffected by $\gamma$-ray irradiation (Figure 1). These results may reflect the hyperresponsiveness of BXSB B cells to T cell-derived stimuli, which is similar to that observed by previous investigators in (NZBxNZW) F1 mice, lpr mice and also SLE patients 


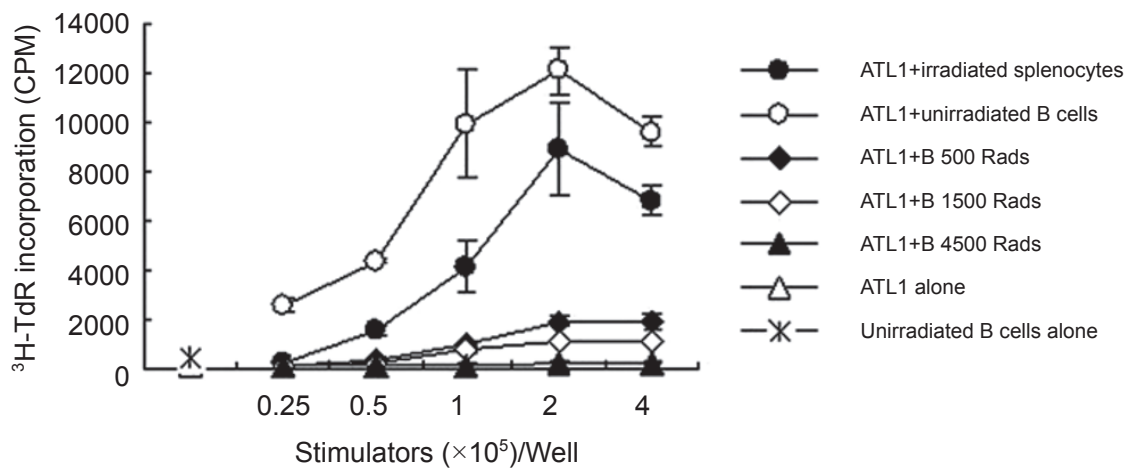

Figure 6 B cells as stimulators for ATL1 cells. B cells were purified to more than $95 \%$ homogeneity from BXSB splenocytes, treated with or without different doses of gamma ray irradiation, and then used as stimulators for ATL1 cells $\left(1 \times 10^{4}\right.$ cells/well $)$ in a proliferation assay. The results are expressed as ${ }^{3} \mathrm{H}-\mathrm{TdR}$ incorporation.

A

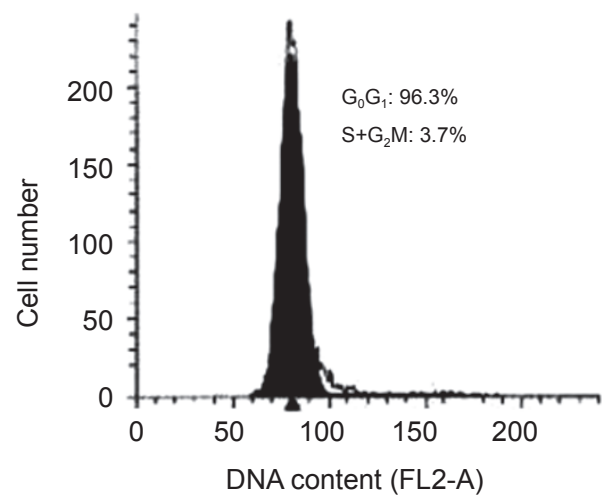

C

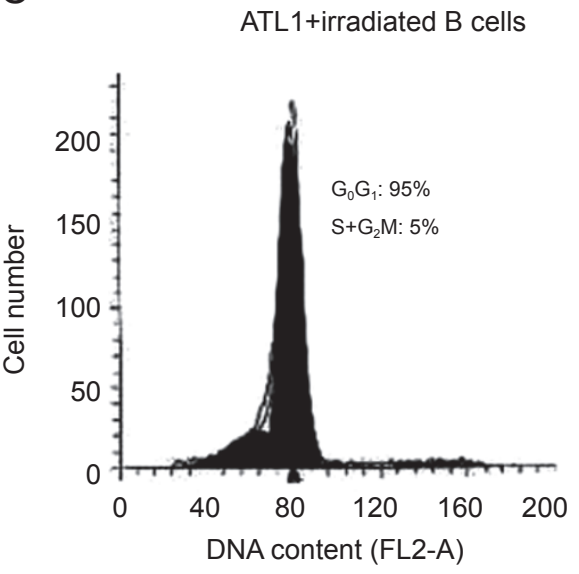

B
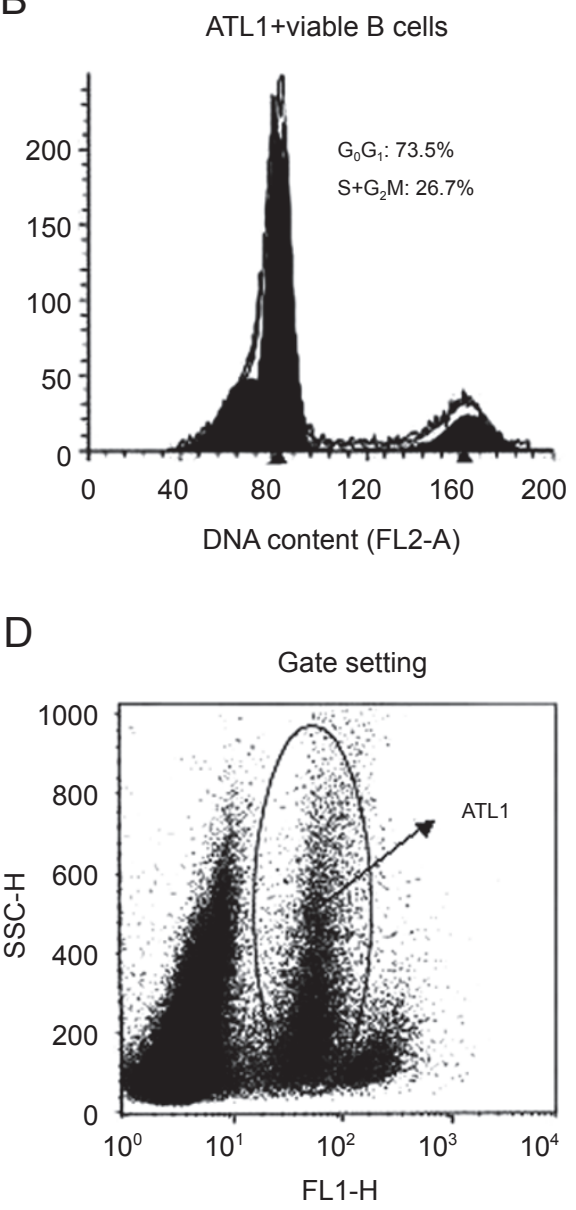

Figure 7 Viable B cells activate ATL1 cells in vitro. CFSE-labeled ATL1 cells were cultured alone (A), or with 1500-Rads-irradiated (B) or untreated (C) B cells freshly purified from 5-month-old male BXSB mice. The cells were harvested $3 \mathrm{~d}$ later, treated with PI immediately before flow cytometric analysis. The gate was set to include CFSE-positive cells only (D). Approximately $25 \%$ ATL1 cells co-cultured with viable $B$ cells were in $S$ or $G_{2} / M$ phase (i.e. in proliferative phase). ATL1 cells stimulated with irradiated B cells failed to display any cell cycle changes as they mostly remained in $\mathrm{G}_{0}$ (resting) phase. 
Table 2 Comparison of ATL1-stimulating properties of various APCs

\begin{tabular}{lcc}
\hline \multicolumn{1}{c}{ Stimulators } & Radiation sensitivity & Optimal R/S ratio \\
\hline Splenocytes & No & $1 / 20$ \\
Splenic adherent cells & No & $1 / 2.5$ \\
B cells & Yes & $1 / 20$ \\
Macrophages & Yes & $1 / 2.5$ \\
DCs & No & $1 / 0.5$ \\
\hline
\end{tabular}

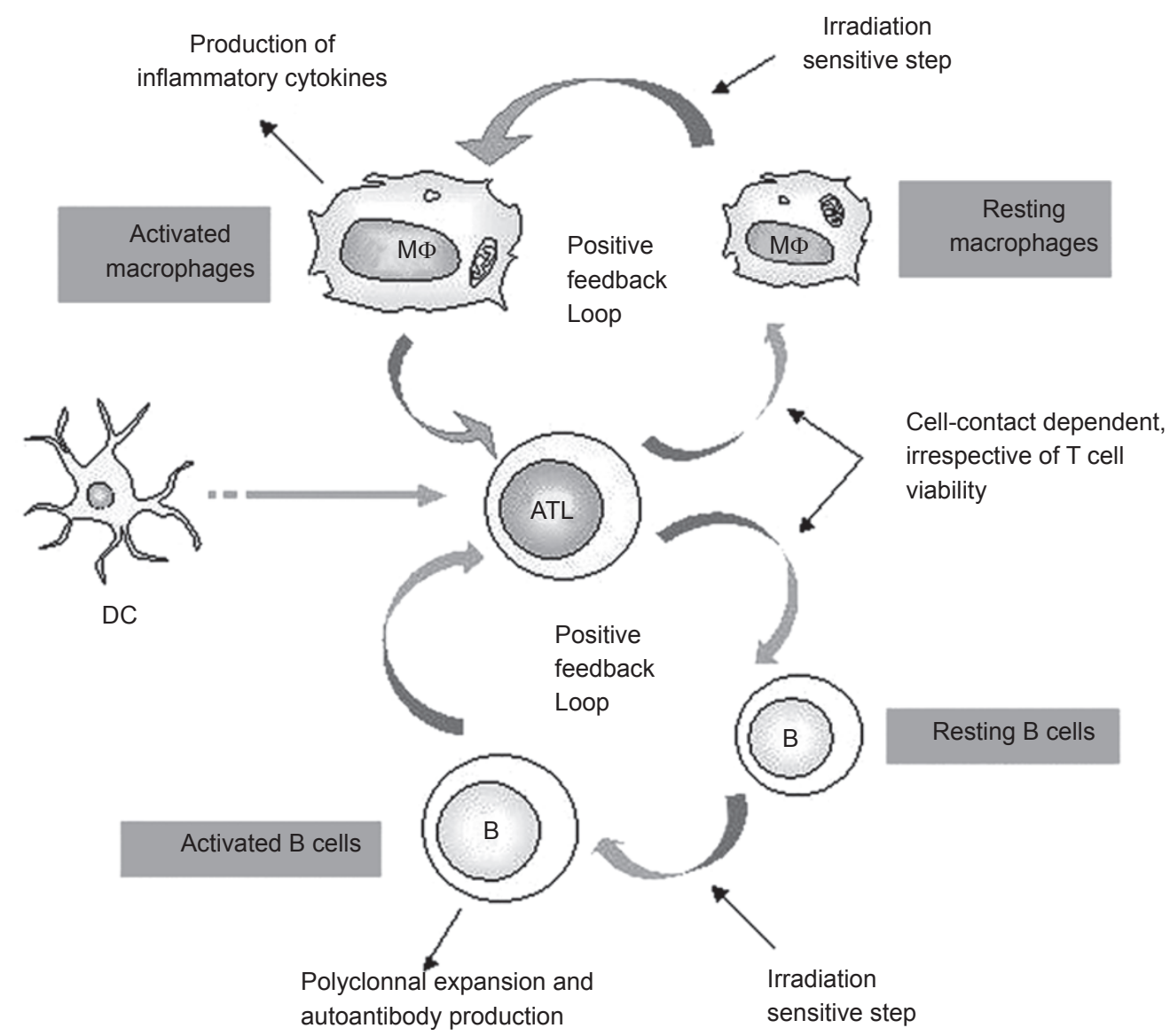

Figure 8 Interaction between autoreactive T cells and their APCs. Autoimmunity is regarded as a continuously evolving process, in which DCs play an important part in activating autoreactive T cells. The autoreactive T cells activate naive B cells and macrophages which can in turn serve as APCs and stimulators for autoreactive T cells. The positive feedback loops between autoreactive T cells, $\mathrm{B}$ cells and macrophages maintain the momentum of autoimmune responses, eventually leading to autoimmune disorders.

[18-21]. It should be noted that abnormal expansion of monocytes/macrophages also occurs in BXSB mice [22, 23]. Mechanisms of cross-talking between BXSB T cells and $\mathrm{B}$ cells are under intensive investigation. It has recently been reported that $\mathrm{B}$ cells containing the Yaa locus are intrinsically biased toward nucleolar antigens because of their increased expression of Toll-like receptor 7 (TLR7), a single-stranded RNA-binding innate immune receptor $[24,35]$. The over-expression of TLR7 increased in vitro responses to TLR7 stimuli in all Yaa-bearing male BXSB mice. In addition, B6.Slelyaa CD4 T cells show expression changes in numerous cytokines and chemokines [25].

Although ATL1 cells are the products of selective expansion of autoreactive $\mathrm{T}$ cells from BXSB mice, freshly 
isolated T cells from the splenocytes of aged BXSB mice did not share the functional ability to activate naive B cells (Figures 1 and 2) and macrophages (data not shown) in vitro. It should be noted that the frequency of autoreactive T cells like ATL1 in the periphery of even aged male BXSB mice is fairly low. By repeated stimulation with syngeneic feeder cells, many autoreactive $T$ cell lines and clones were generated from the splenocytes of aged male BXSB mice [6]. However, no such autoreactive $\mathrm{T}$ cell lines or clones were obtained from $\mathrm{C} 57 \mathrm{BL} / 6$ or $\mathrm{BALB} / \mathrm{c}$ mice of the same age and sex, by using the same protocol (data not shown). It is thus likely that autoreactive nature of ATL1 cells was caused by the intrinsic genetic make-up in BXSB mice. However, it is unlikely that the phenotypical and functional characteristics of ATL1 cells were simply the results of long-term tissue culture.

Compared with B cells and macrophages, DCs were much more powerful stimulators for ATL1 cells on a per cell basis (Table 2). The ATL1-stimulating ability of DCs was resistant to irradiation treatment (Figure 5). DCs from C57BL/6 mice were significantly less stimulatory than that from BXSB mice (Li B, unpublished observation), suggesting that abnormalities of BXSB DCs enhanced their T-cellstimulating ability. Such "super" DCs may play a pivotal role in the development of autoimmune diseases, a notion supported by the fact that DCs with aberrant function were also found in murine lupus and NOD model of diabetes [26]. Vasquez et al. observed qualitative and quantitative abnormalities in splenic dendritic cell populations in NOD mice [27]. Increased generation of DCs from myeloid progenitors in autoimmune-prone NOD mice has also been reported [28]. Intravenous injection of BM-derived DCs pulsed with U1 snRNP-A protein into BALB/c and DBA- $2 \times$ NZW F1 $\left(\mathrm{H}-2^{\mathrm{d} / \mathrm{u}}\right)$ mice elicited autoreactive T cell and IgG anti-U1A responses [29]. Chronic maturation of tissue DCs could induce severe organ-specific autoimmune disease and systemic autoimmunity [30-32]. In addition, transfer of DCs, isolated from donors with acute autoimmune disease or propagated in vitro under conditions that induce maturation, generates a strong Th- 1 response and eventually leads to autoimmune disease such as EAE and diabetes in mice [33-34].

Both resting $B$ cells and macrophages were sensitive to irradiation when employed as stimulators for ATL1 cells (Figures 4,6), indicating that they only acquire the ability to stimulate autoreactive $\mathrm{T}$ cells after their activation by ATL1 cells. Interestingly, the expression of B7.1, one of the major co-stimulatory molecules on B cells, is up-regulated in BXSB B cells (Figure 2) and peritoneal macrophages (data not shown) after stimulation by ATL1. Thus, autoreactive T cells, B cells and macrophages could form feedback loops in which the T cells activate $B$ cells and macrophages first, thereby enabling them to function as APCs for the T cells and help maintain the momentum of T cell expansion in vivo (Figure 8).

Taken together, our data suggest that positive feedback loops involving macrophages, $\mathrm{B}$ cells and autoreactive $\mathrm{T}$ cells may become driving forces for the development of autoimmune responses (Figure 8). Further analysis of Tcell-APC interaction should shed light on novel avenues of treatment aimed at correcting (or interfering with) the pathogenic APC-T-cell interaction in autoimmune disorders.

\section{Acknowledgment}

This study was supported by grants from the National Key Basic Research Programs (2001CB510007) and National Natural Science Foundation of China (30371303).

\section{References}

1 Klinman DM, Steinberg AD. Inquiry into murine and human lupus. Immunol Rev 1995; 144:157-193.

2 Shivakumar S, Tsokos GL, Data SK. T cell $\alpha / \beta$ receptor expressing double-negative (CD4/ $\left.{ }^{-} \mathrm{CD} 8^{-}\right)$and $\mathrm{CD} 4^{+} \mathrm{T}$ helper cells in human augment the production of pathogenic anti-DNA antibodies in association with lupus nephritis. J Immunol 1989; 143:103-112.

3 Kyttaris VC, Tsokos GC. T lymphocytes in systemic lupus erythematosus: an update. Curr Opin Rheumatol 2004; 16:548-552.

4 Ando AG, Sercare EE, and Hahn BH. Mechanism of T and B cell collaboration in the in vitro production of anti-DNA antibodies in the NZB $\times$ SWR model of lupus nephritis. J Immunol 1987; 140:2215-2222.

5 Lang TJ, Nguyen P, Papadimitriou JC, Via CS. Increased severity of murine lupus in female mice is due to enhanced expansion of pathogenic T cells. J Immunol 2003; 171:5795-5801.

6 Han SH, Li B, Chen YT, Gao XM. Isolation and functional analysis of auto-reactive T cells from BXSB mice with murine lupus. J Autoimmun 2002; 19:45-54.

7 Takeno M, Nagafuchi H, Kaneko S, et al. Autoreactive T cell clones from patients with systemic lupus erythematosus support polyclonal autoantibody production. J Immunol 1997; 158:35293538.

8 Busser BW, Cancro MP, Laufer TM. An increased frequency of autoantibody-inducing $\mathrm{CD} 4^{+} \mathrm{T}$ cells in pre-diseased lupus-prone mice. Int Immunol 2004; 16:1001-1007.

9 Zielinski CE, Jacob SN, Bouzahzah F, Ehrlich BE, Craft J. Naive $\mathrm{CD}^{+} \mathrm{T}$ cells from lupus-prone Fas-intact MRL mice display TCR-mediated hyperproliferation due to intrinsic threshold defects in activation. J Immunol 2005; 174:5100-5109.

10 Zhu J, Liu X, Xie C, et al. T cell hyperactivity in lupus as a consequence of hyperstimulatory antigen-presenting cells. J Clin Invest 2005; 115:1869-1878.

11 Murphy ED, Roth JB. New inbred strains. Mouse News Lett 1978; 58:51-52.

12 Merino R, Fossati L, Lacour M, et al. H-2-linked control of the Yaa gene-induced acceleration of lupus-like autoimmune disease 
in BXSB mice. Eur J Immunol 1992; 22:295-299.

13 Izui S, Iwamoto M, Fossati L, Merino R, Takahashi S and IbnouZekri N. The Yaa gene model of systemic lupus erythematosus. Immunol Rev 1995; 144:137-156.

14 Hogarth MB, Slingsby JH, Allen PJ, et al. Multiple lupus susceptibility loci map to chromosome 1 in BXSB mice. J Immunol 1998; 161:2753-2761.

15 Haywood MK, Hogarth MB, Slingsby JH, et al. Identification of intervals on chromosome 1, 3 and 13 linked to the development of lupus in BXSB mice. Arthritis Reum 2000; 349-355.

16 Maibaum MA, Haywood MEK, Walport MJ, Morley BJ. Lupus susceptibility loci within regions of BXSB derived from the SB/Le parental strain. Immunogenetics 2000; 51:370-372.

17 Son YI, Egawa S, Tatsumi T, Redlinger RE Jr, Kalinski P, Kanto T. A novel bulk-culture method for generating mature dendritic cells from mouse bone marrow cells. J Immunol Methods 2002; 262:145-157.

18 Reininger L, Winkler TH, Kalberer CP, et al. Intrinsic B cell defects in NZB and NZW F1 mice contribute to systemic lupus erythematosus in (NZBxNZW) F1 mice. J Exp Med 1996; 184:853-860.

19 Sobel ES, Katagiri T, Morris SC, et al. An intrinsic B cell defect is required for the production of autoantibodies in the lpr model of murine systemic autoimmunity. J Exp Med 1991; 173:14411449.

20 Jongstra-Bilen J, Vukusic B, Boras K and Wither JE. Resting B cells from autoimmune lupus-prone NZB and (NZBxNZW) F1 mice are hyper-responsive to T cell-derived stimuli. J Immunol 1997; 159:5810-5820.

21 Inghirami G, Simon J, Balow JE, et al. Activated T lymphocytes in the peripheral blood of patients with systemic lupus erythematosus induce B cells to produce immunoglobulin. Clin Exp Rheumatol 1988; 6:269-276.

22 Wofsy D, Kerger CE, Seaman WE. Monocytosis in the BXSB model for systemic lupus erythematosus. J Exp Med 1984; 159:629-634.

23 Vieten G, Hadam MR, De Boer H, Olp A, Fricke M, Hartung $\mathrm{K}$. Expanded macrophage precursor populations in BXSB mice: possible reason for the increasing monocytosis in male mice. Clin
Immunol Immunopathol 1992; 65:212-218.

24 Pisitkun P, Deane JA, Difilippantonio MJ, Tarasenko T, Satterthwaite AB, Bolland S. Autoreactive B cell responses to RNArelated antigens due to TLR7 gene duplication. Science 2006, 16; 312:1669-1672.

25 Subramanian S, Tus K, Li QZ, et al. A Tlr7 translocation accelerates systemic autoimmunity in murine lupus. Proc Natl Acad Sci USA 2006; 103:9970-9975.

26 Bayry J, Thirion M, Delignat S, et al. Dendritic cells and autoimmunity. Autoimmun Rev 2004; 3:183-187.

27 Vasquez AC, Feili-Hariri M, Tan RJ, Morel PA. Qualitative and quantitative abnormalities in splenic dendritic cell populations in NOD mice. Clin Exp Immunol 2004; 135:209-218.

28 Steptoe RJ, Ritchie JM, Harrison LC. Increased generation of dendritic cells from myeloid progenitors in autoimmune-prone nonobese diabetic mice. J Immunol 2002; 168:5032-5041.

29 Suen JL, Chuang YH, Chiang BL. In vivo tolerance breakdown with dendritic cells pulsed with U1A protein in non-autoimmune mice: the induction of a high level of autoantibodies but not renal pathological changes. Immunology 2002; 106:326-335.

30 Jansen A, van Hagen M, and Drexhage HA. Defective maturation and function of antigen-presenting cells in type 1 diabetes. Lancet 1995; 345:491-492.

31 Scheinecker C, Zwolfer B, Koller M, Manner G, Smolen JS. Alterations of dendritic cells in systemic lupus erythematosus: phenotypic and functional deficiencies. Arthritis Rheum 2001; 44:856-865.

32 Ma L, Chan KW, Trendell-Smith NJ, et al. Systemic autoimmune disease induced by dendritic cells that have captured necrotic but not apoptotic cells in susceptible mouse strains. Eur J Immunol 2005; 35:3364-3375.

33 Dittel BN, Visintin I, Merchant RM, Janeway CA Jr. Presentation of the self-antigen myelin basic protein by dendritic cells leads to experimental autoimmune encephalomyelitis. J Immunol 1999; 163:32-39.

34 Ludewig B, Odermatt B, Landmann S, Hengartner H. Dendritic cells induce autoimmune diabetes and maintain disease via de novo formation of local lymphoid tissue. J Exp Med 1998; 188:1493-1501. 